\title{
Two novel 1,4-naphthoquinone derivatives induce human gastric cancer cell apoptosis and cell cycle arrest by regulating reactive oxygen species-mediated MAPK/Akt/STAT3 signaling pathways
}

\author{
HAO WANG ${ }^{1 *}$, YING-HUA LUO ${ }^{2 *}$, GUI-NAN SHEN ${ }^{1 *}$, XIAN-JI PIAO ${ }^{3}$, WAN-TING XU ${ }^{1}$, YI ZHANG ${ }^{1}$ \\ JIA-RU WANG ${ }^{1}$, YU-CHAO FENG ${ }^{1}$, JIN-QIAN LI ${ }^{1}$, YU ZHANG ${ }^{1}$, TONG ZHANG ${ }^{1}$, SHI-NONG WANG ${ }^{1}$, \\ HUI XUE ${ }^{1}$, HONG-XING WANG ${ }^{1}$, CHANG-YUAN WANG ${ }^{4}$ and CHENG-HAO JIN ${ }^{1,4}$ \\ ${ }^{1}$ Department of Biochemistry and Molecular Biology, College of Life Science and Technology and \\ ${ }^{2}$ Department of Grass Science, College of Animal Science and Veterinary Medicine, \\ Heilongjiang Bayi Agricultural University, Daqing, Heilongjiang 163319; ${ }^{3}$ Department of \\ Gynaecology and Obstetrics, The Fifth Affiliated Hospital of Harbin Medical University, \\ Daqing, Heilongjiang 163316; ${ }^{4}$ Department of Food Science and Engineering, College of Food Science, \\ Heilongjiang Bayi Agricultural University, Daqing, Heilongjiang 163319, P.R. China
}

Received November 9, 2018; Accepted April 12, 2019

DOI: $10.3892 / \mathrm{mmr} .2019 .10500$

\begin{abstract}
Naphthoquinone derivatives have superior anticancer effects, but their use has been severely limited in clinical practice due to adverse side effects. To reduce the side effects and extend the anticancer effects of 1,4-naphthoquinone derivatives, 2-(butane-1-sulfinyl)-1,4-naphthoquinone (BQ) and 2-(octane-1-sulfinyl)-1,4-naphthoquinone (OQ) were synthesized, and their anticancer activities were investigated. The anti-proliferation effects, determined by MTT assays, showed that BQ and OQ significantly inhibited the viability of gastric cancer cells and had no significant cytotoxic effect on normal cell lines. The apoptotic effect was determined by flow cytometry, and the results showed that BQ and OQ induced cell apoptosis by regulating the mitochondrial pathway and cell cycle arrest at the G2/M phase via inhibition of the Akt
\end{abstract}

Correspondence to: Professor Cheng-Hao Jin, Department of Biochemistry and Molecular Biology, College of Life Science and Technology, Heilongjiang Bayi Agricultural University, 5 Xinfa Street, Daqing, Heilongjiang 163319, P.R. China

E-mail: jinchenghao3727@qq.com

Professor Chang-Yuan Wang, Department of Food Science and Engineering, College of Food Science, Heilongjiang Bayi Agricultural University, 5 Xinfa Street, Daqing, Heilongjiang 163319, P.R. China

E-mail: 763002133@qq.com

${ }^{*}$ Contributed equally

Key words: 1,4-naphthoquinone derivatives, human gastric cancer cells, mitochondrial-dependent apoptosis, cell cycle arrest, reactive oxygen species, MAPK, STAT3, Akt signaling pathway in AGS cells. Furthermore, BQ and OQ significantly increased the levels of reactive oxygen species (ROS) and this effect was blocked by the ROS scavenger NAC in AGS cells. BQ and OQ induced apoptosis by upregulating the protein expression of $\mathrm{p} 38$ and JNK and downregulating the levels of ERK and STAT3. Furthermore, expression levels of these proteins were also blocked after NAC treatment. These results demonstrated that $\mathrm{BQ}$ and $\mathrm{OQ}$ induced apoptosis and cell cycle arrest at the G2/M phase in AGS cells by stimulating ROS generation, which caused subsequent activation of MAPK, Akt and STAT3 signaling pathways. Thus, BQ and OQ may serve as potential therapeutic agents for the treatment of human gastric cancer.

\section{Introduction}

Gastric cancer is a malignant tumor that accounts for $7 \%$ of all human cancers. It is one of the leading causes of cancer-related deaths, with about 1.4 million new cases diagnosed worldwide (1). Since the rise and development of chemotherapy in recent decades, it has become a feasible therapeutic strategy for gastric cancer treatment, but these chemotherapeutic drugs represented by 5 -fluorouracil (5-FU) and shikonin have limited clinical applications due to severe side effects $(2,3)$. Therefore, there is an urgent need to identify novel chemotherapeutic drugs that improve the therapeutic effects for gastric cancer.

Induction of apoptosis or cell cycle arrest is considered to be an important means for exerting an anticancer effect characteristic of chemotherapy drugs (4). Apoptosis can be activated through two pathways: Mitochondria-dependent and mitochondria-independent pathways (5). The mitochondria-dependent pathway of apoptosis is regulated by the B-cell lymphoma 2 (Bcl-2) family of proteins. The balance between Bcl-2-associated death promoter (Bad) and Bcl-2 proteins regulates the activation of caspase-3, ultimately 
leading to mitochondrial apoptosis (6). The cell cycle is the basic process underlying biological activity and cell cycle arrest can lead to apoptosis. Many anticancer drugs block the cell cycle at specific checkpoints through the Akt signaling pathway, thereby inducing apoptosis in cancer cells. The cyclin-dependent kinase/cyclin complex plays a significant role in cell cycle regulation (7-9).

Growing evidence has shown that the generation of reactive oxygen species (ROS) and relevant signaling pathways play critical roles in the apoptosis of cancer cells (10). Recent research has demonstrated ROS-mediated mitogen-activated protein kinase (MAPK) activation in apoptosis triggered by various stimuli (11). The protein kinase B (Akt) signaling pathway, an intracellular regulator of multiple pathways that play fundamental roles in apoptosis and cell cycle arrest, can be modulated by ROS (12). It has also been suggested that ROS are important cellular mediators that trigger activation of the signal transducer and activator of transcription 3 (STAT3)-dependent pathway after chemotherapeutic drug administration (13).

1,4-Naphthoquinone exhibits a variety of biological activities, and its superior anticancer activity has attracted widespread attention $(14,15)$. Many 1,4-naphthoquinone derivatives (plumbagin, mitomycin and shikonin) have been demonstrated to strongly inhibit the proliferation and induce apoptosis in cancer cells, but most of the derivatives also cause adverse side effects in normal cells (16). Previous studies have demonstrated that different substituent structures enable naphthoquinone derivatives to have different biological activities $(17,18)$. Therefore, substitution of a molecular group has been investigated as an effective strategy to develop anticancer drugs. The biological activity and toxic side effects of naphthoquinone derivatives are correlated with the structure. The length of the alkane chain on the $\mathrm{C} 2$ position can affect the biological activity of these compounds $(19,20)$.

Here, we increased the fat solubility of the compounds and studied the effects of carbon chain length on their anticancer activity. Based on the principles of structural design, two 1,4-naphthoquinone derivatives named 2-(butane-1-sulfinyl)-1,4-naphthoquinone (BQ) and 2-(octane-1-sulfinyl)-1,4-naphthoquinone (OQ) were synthesized to reduce the toxicity and optimize the efficacy of these agents. Then their effects on anti-proliferation, apoptosis induction, cell cycle arrest and ROS generation in gastric cancer cells were evaluated. The molecular mechanisms of apoptosis induced by BQ and OQ were then explored using AGS gastric cancer cells.

\section{Materials and methods}

Synthesis of the 1,4-naphthoquinone derivatives $B Q$ and $O Q$. 1,4-Naphthoquinone $(0.5 \mathrm{mM})$ was dissolved in $\mathrm{MeOH}(15 \mathrm{ml})$, and alkyl thiol $(0.75 \mathrm{mM})$ was added to this solution and then stirred for $4 \mathrm{~h}$ at room temperature. Sodium dichromate $(0.1 \mathrm{mM})$ and sulfuric acid $(0.4 \mathrm{mM})$ were added to the mixture dropwise and then stirred for $0.5 \mathrm{~h}$ at room temperature. The mixture was extracted with dichloromethane and brine, dried over anhydrous sodium sulfate, filtered, and concentrated under reduced pressure. M-CPBA $(0.6 \mathrm{mM})$ was added to this mixture in chloroform $(10 \mathrm{ml})$ and stirred at $0^{\circ} \mathrm{C}$ for $1 \mathrm{~h}$. At the end of the reaction, $5 \% \mathrm{NaHCO}_{3}$ was added to this mixture. Then the solution was extracted with dichloromethane and brine, dried over anhydrous sodium sulfate, filtered, and concentrated under reduced pressure. The residue underwent chromatography to obtain 2-(butane-1-sulfinyl)-1,4-naphthoquinone (BQ) and 2-(octane-1-sulfinyl)-1,4-naphthoquinone (OQ).

Chemicals and materials. Reagents were freshly diluted to the desired concentration with the culture medium before use. Fetal bovine serum (FBS), Roswell Park Memorial Institute 1640 (RPMI 1640), Dulbecco's modified Eagle's medium (DMEM), penicillin $(100 \mathrm{U} / \mathrm{ml})$, and streptomycin $(100 \mu \mathrm{g} / \mathrm{ml})$ were purchased from Gibco (Thermo Fisher Scientific, Inc.). The Annexin V-FITC Apoptosis Detection Kit, Cell Cycle Detection Kit, 2'7'-dichlorofluorescein diacetate (DCFH-DA), and $\mathrm{N}$-acetyl-L-cysteine (NAC) were purchased from Beyotime Institute of Biotechnology. DMSO was obtained from Sigma-Aldrich (Merck KGaA). All primary antibodies used in the present study were purchased from Santa Cruz Biotechnology, Inc. and all secondary antibodies used were purchased from ZSGB-BIO.

Cell lines and cell culture. All eight gastric cancer cell lines (AGS, MKN-45, NCI-N87, SUN-5, KATO-3, YCC-1, YCC-6, YCC-16 and SNU-5) were purchased from the American Type Culture Collection. Normal stomach GES-1 and normal liver L-02 cell lines and human lung fibroblasts (IMR-90) were obtained from Saiqi Biotech Co., Ltd. This study investigated the effects of $\mathrm{BQ}$ and $\mathrm{OQ}$ on gastric cancer cells, and we selected a normal gastric cell line to evaluate toxicity and side effects. The GES-1 cell line is a type of normal gastric mucosal epithelial cell line that grows in the stomach, thus we chose GES-1 as a control. The liver is the important target organ for drug toxicity testing, and can directly reflect toxic effects in toxicity studies. In addition, IMR-90 cells were extracted from human lung tissue, and their primary properties were not transformed, which can directly reflect the toxic effects in toxicity studies. For this reason, GES-1, L-02 and IMR-90 cell lines were chosen as controls. AGS, MKN-45, KATO-3 and SNU-5 cells were cultured in RPMI-1640 medium, and the remaining cell lines were cultured in DMEM. RPMI-1640 medium or DMEM contained $10 \%$ heat-inactivated FBS, $100 \mathrm{U} / \mathrm{ml}$ penicillin, and $100 \mu \mathrm{g} / \mathrm{ml}$ streptomycin. All cells were maintained at $37^{\circ} \mathrm{C}$ in a humidified atmosphere with $5 \% \mathrm{CO}_{2}$.

MTT assay. Cytotoxicity was measured using an MTT assay. Briefly, the eight gastric cancer cell lines and the three normal cell lines were treated with $\mathrm{BQ}, \mathrm{OQ}, 5-\mathrm{FU}$ or shikonin at different concentrations. At the end of the treatment, $15 \mu \mathrm{l}$ MTT was added to each well and $100 \mu 1$ DMSO was added to each well after the cells were incubated for another $15 \mathrm{~min}$. Absorbance at $490 \mathrm{~nm}$ was measured by microplate illuminometer (BioTek Instruments, Inc.), and the results were used to calculate cell viability.

Cell apoptosis analysis. The effects of $\mathrm{BQ}$ and $\mathrm{OQ}$ on the apoptosis of AGS cells were quantitated using the Annexin V-FITC Apoptosis Detection Kit (Beyotime Institute of Biotechnology) 
A

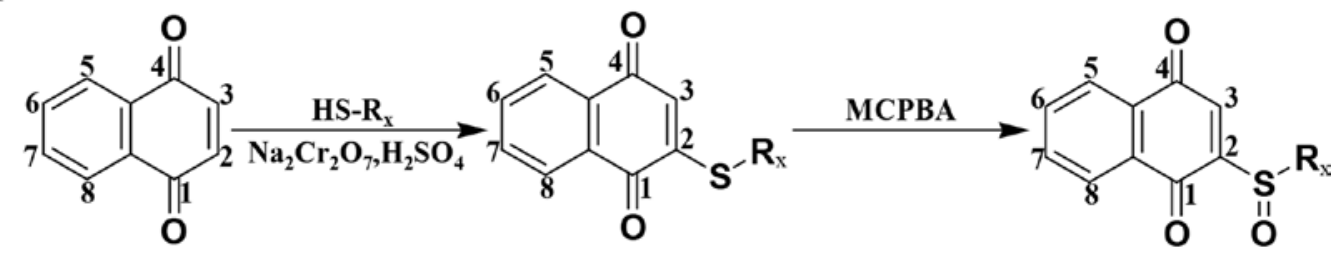

HS- $\mathbf{R}_{1}$ : $\mathrm{HS}-\left(\mathrm{CH}_{2}\right)_{3} \mathrm{CH}_{3}$ HS- $\mathrm{R}_{2}: \mathrm{HS}-\left(\mathrm{CH}_{2}\right)_{7} \mathrm{CH}_{3}$

B

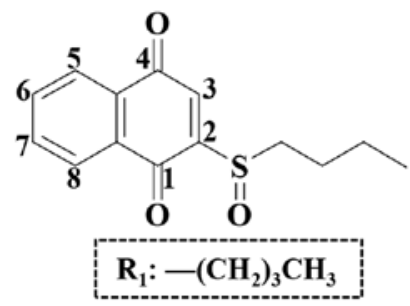

2-(butane-1-sulfinyl)-1,4-naphthoquinone (BQ)

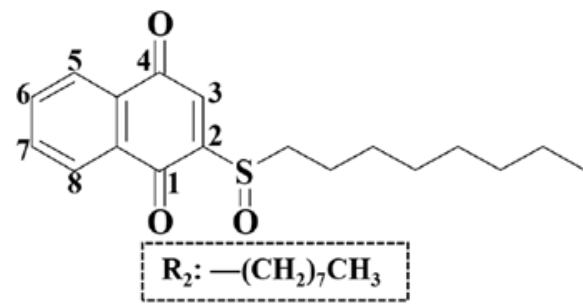

2-(octane-1-sulfinyl)-1,4-naphthoquinone (OQ)

Figure 1. (A) Synthetic route and (B) chemical structure of BQ and OQ.

and flow cytometry. AGS cells were treated with BQ, OQ, or 5-FU at a concentration of $3 \mu \mathrm{M}$ for $3,6,12$ or $24 \mathrm{~h}$. A volume of $200 \mu \mathrm{l}$ binding buffer was incubated with AGS cells, followed by staining with $3 \mu \mathrm{l}$ Annexin V-FITC and $2 \mu \mathrm{l}$ propidium iodide (PI) at the $4^{\circ} \mathrm{C}$ for $30 \mathrm{~min}$. The stained AGS cells were observed using the EVOS FL Auto Cell Imaging System (Thermo Fisher Scientific, Inc.) at a magnification of $\mathrm{x} 400$, and analyzed using a flow cytometer (Beckman Coulter, Inc.). Data were analyzed using CytExpert software 2.0 (Beckman Coulter, Inc.).

Cell cycle analysis. The cell cycle was detected using a Cell Cycle Detection kit (Beyotime Institute of Biotechnology, Shanghai, China) and flow cytometry. AGS cells were treated with $3 \mu \mathrm{M}$ BQ or OQ for $3,6,12$ or $24 \mathrm{~h}$. The cells were harvested, incubated with $70 \%$ cold ethanol at $-20^{\circ} \mathrm{C}$ for $12 \mathrm{~h}$, washed with PBS, and stained with PI $(10 \mu \mathrm{g} / \mathrm{ml}) / \mathrm{RNase}$ staining buffer (Beyotime Institute of Biotechnology). The staining took place at $4^{\circ} \mathrm{C}$ for $30 \mathrm{~min}$ in the dark. Samples were analyzed with a flow cytometer (Beckman Coulter, Inc.). Data were analyzed using CytExpert software 2.0 (Beckman Coulter, Inc.).

Measurement of ROS. To determine the intracellular levels of ROS, DCFH-DA was utilized. AGS cells were plated in 6-well plates and grown to $60 \%$ confluence. AGS cells were treated with $3 \mu \mathrm{M}$ BQ or OQ for 3,6, 12 or $24 \mathrm{~h}$. Cells were harvested, stained with $10 \mu \mathrm{M}$ DCFH-DA for $30 \mathrm{~min}$ at $37^{\circ} \mathrm{C}$, washed twice with PBS, and then immediately analyzed by flow cytometry (Beckman Coulter, Inc.). ROS levels were analyzed using CytExpert software 2.0 (Beckman Coulter, Inc.).

Western blot analysis. Western blot analysis was performed using standard methods. AGS cells were normally cultured and treated with $3 \mu \mathrm{M}$ BQ or OQ for 3, 6, 12 or $24 \mathrm{~h}$. Cells were lysed in lysis buffer containing protease inhibitors $(50 \mathrm{mmol} / 1$ Tris (pH 7.4), $150 \mathrm{mmol} / \mathrm{l} \mathrm{NaCl}, 1 \%$ Triton $\mathrm{X}-100,1 \%$ sodium deoxycholate, $0.1 \% \mathrm{SDS}, 20 \mathrm{mg} / \mathrm{ml}$ AEBSF, $0.5 \mathrm{mg} / \mathrm{ml}$ pepstatin, $0.5 \mathrm{mg} / \mathrm{ml}$ leupeptin and $2 \mathrm{mg} / \mathrm{ml}$ aprotinin), and the supernatant was collected followed by centrifugation at $16,000 \mathrm{x} \mathrm{g}$ for $30 \mathrm{~min}$ at $4^{\circ} \mathrm{C}$, and total protein was quantified using coomassie blue staining. A total of $20 \mu \mathrm{l}$ protein samples were separated on $8-12 \%$ SDS-PAGE, and electrophoretically transferred to nitrocellulose membranes. After blocking in $5 \%$ skimmed milk at $37^{\circ} \mathrm{C}$ for $2 \mathrm{~h}$, the membrane was incubated overnight at $4^{\circ} \mathrm{C}$ with a primary antibody against mouse monoclonal $\alpha$-tubulin (1:2,500; cat. no. sc-8035), Bad (1:1,500; cat. no. sc-8044), Bcl-2 (1:1,500; cat. no. sc-7382), pro-PARP (1:1,500; cat. no. sc-74469), cleaved poly (ADP ribose) polymerase 1 (cle-PARP; 1:1,500; cat. no. sc-8007), pro-caspase-3 (pro-cas-3; 1:1,500; cat. no. sc-7272); cleaved-caspase-3 (cle-cas-3; 1:1,500; cat. no. sc-373730), phosphorylated (p-) extracellular signal-regulated kinase (ERK) $\left(\mathrm{Tyr}^{204}, 1: 1,500\right.$; cat. no. sc-8059), p-JNK (Tyr ${ }^{183}$ and $\mathrm{Tyr}^{185}$; 1:1,500; cat. no. sc-6254), JNK (1:1,500; cat. no. sc-7345), p-p38 (Tyr ${ }^{182}, 1: 1,500$; cat. no. sc-7973), p-STAT3 (Tyr ${ }^{705}$, 1:1,500; cat. no. sc-8059), STAT3 (1:1,500; cat. no. sc-8019), cyclin-dependent 1/2 (CDK1/2) (1:1,500; cat. no. sc-53219), cyclin B1 (1:1,500; cat. no. sc-166210), rabbit polyclonal ERK (1:1,500; cat. no. sc-154), p38 (1:1,500; cat. no. sc-7972), Akt (1:1,500; cat. no. sc-271149), p-Akt (1:1,500; cat. no. sc-135651) and p27 (1:1,500; cat. no. sc-1641). This was followed by incubation with horseradish peroxidase-conjugated anti-mouse (1:5,000; cat. no. ZB-2301) and anti-rabbit immunoglobulin G (1:5,000; cat. no. ZB-2305) secondary antibodies for $2-3 \mathrm{~h}$ at room temperature. The proteins were visualized using ECL reagents and the AI600 Imager (GE Healthcare). The blots were analyzed using ImageJ 1.46r software (National Institutes of Health), and protein levels were normalized to the matching densitometry value of $\alpha$-tubulin as the internal control.

Statistical analysis. Data are presented as the mean \pm standard deviation of three independent experiments. The samples of each group were compared by analysis of variance, and 

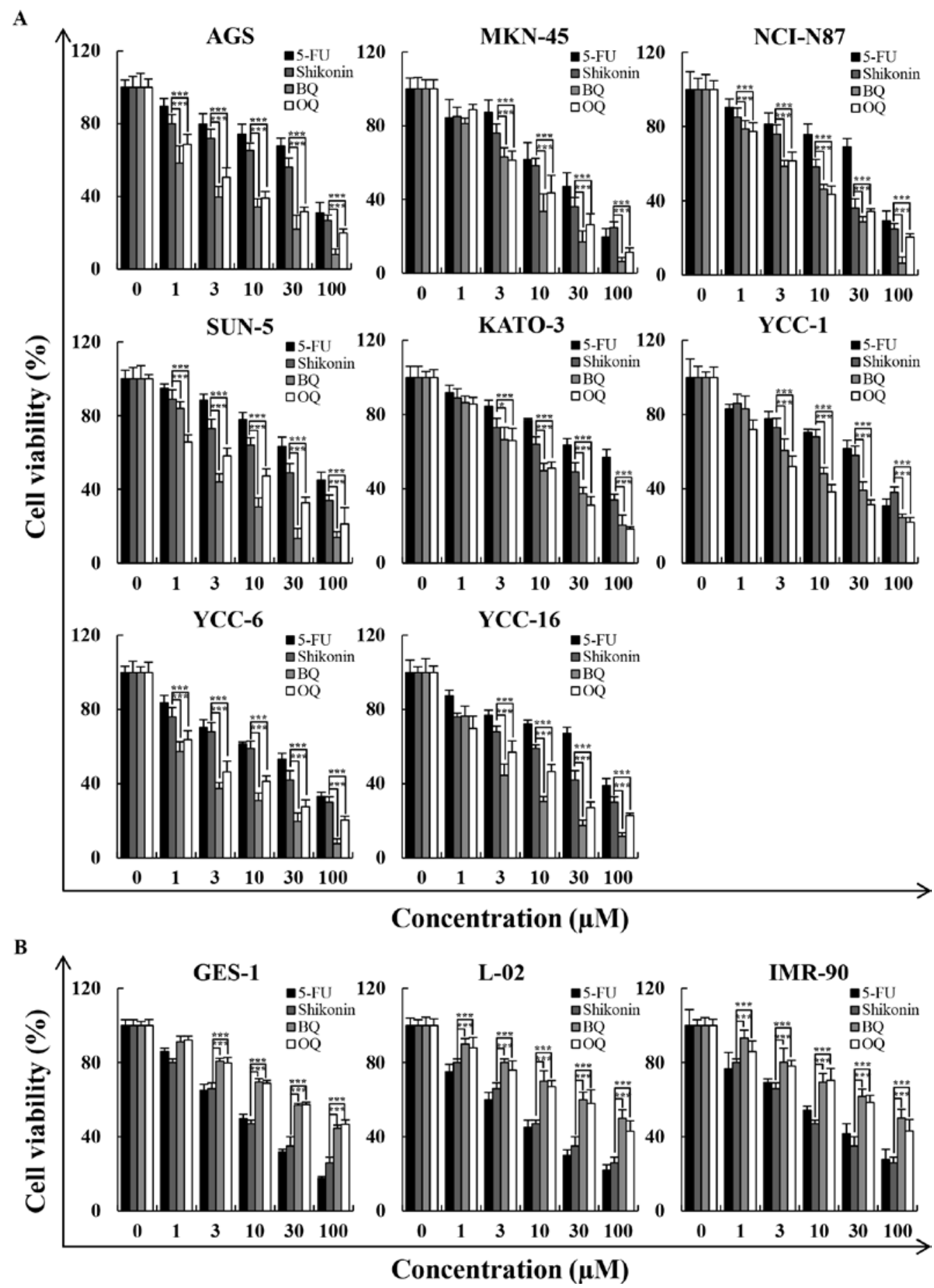

Figure 2. Cytotoxic effects of 5-FU, shikonin, BQ and OQ on eight gastric cancer cell lines, as determined by MTT assay. (A) Eight gastric cancer cell lines were treated with different concentrations of 5-FU, shikonin, BQ and OQ for $24 \mathrm{~h}$. (B) Three normal cell lines were treated with different concentrations of 5-FU, shikonin, BQ and OQ for $24 \mathrm{~h}$. Data are expressed as the means \pm standard deviation of the results from three independent experiments. "P $<0.05$ and ${ }^{* * *} \mathrm{P}<0.001$. 5-FU, 5-fluorouracil; BQ, 2-(butane-1-sulfinyl)-1,4-naphthoquinone; OQ, 2-(octane-1-sulfinyl)-1,4-naphthoquinone.

multiple comparisons between groups were performed using one-way analysis of variance followed by Tukey's post hoc tests using SPSS version 18.0 statistical software (SPSS, Inc.). $\mathrm{P}<0.05$ was considered to indicate a statistically significant difference.

\section{Results}

Structure and synthetic route of the two derivatives. To improve the anticancer activity and reduce the adverse side effects, BQ and OQ were synthesized by performing a series of steps to modify the 1,4-naphthoquinone chemical structure (Fig. 1). By performing nuclear magnetic resonance at a wavelength of $400 \mathrm{MHz}$, we analyzed the $\mathrm{H}$ and $\mathrm{C}$ spectra in deuterated chloroform solvent.

Effects of $B Q$ and $O Q$ on the proliferation of gastric cancer cells. The results of the MTT assays showed that BQ and OQ significantly decreased the viability of human gastric cancer cells in a dose-dependent manner, and the pro-apoptotic 

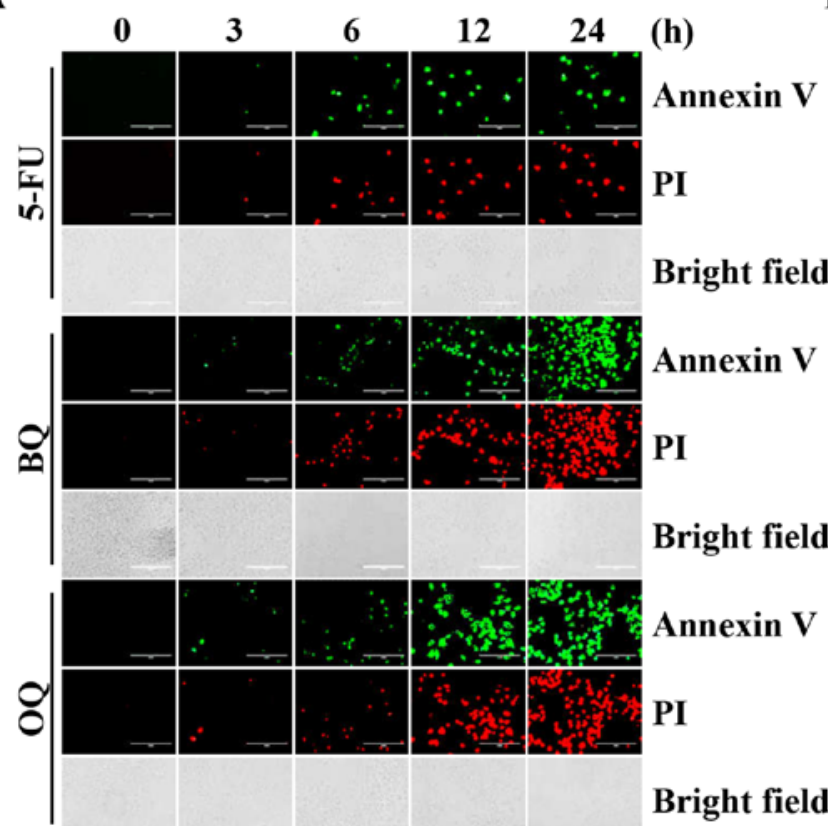

C

C
$\overline{\mathbf{a}}$

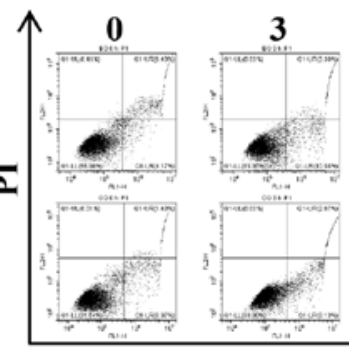

E
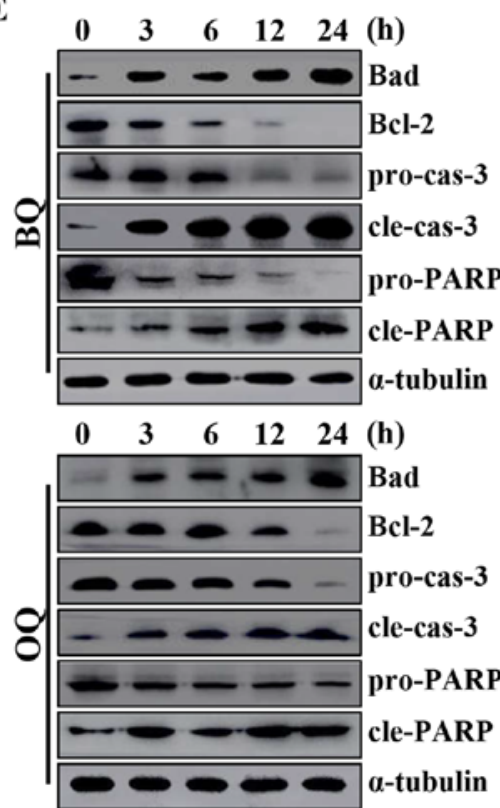

Bright field

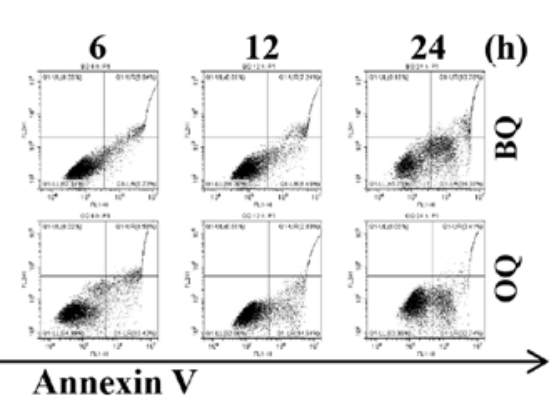

B

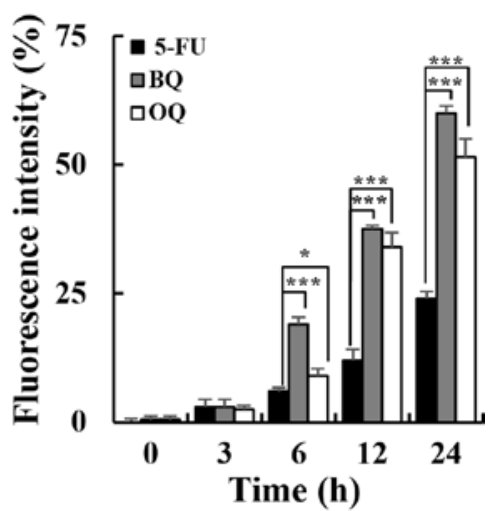

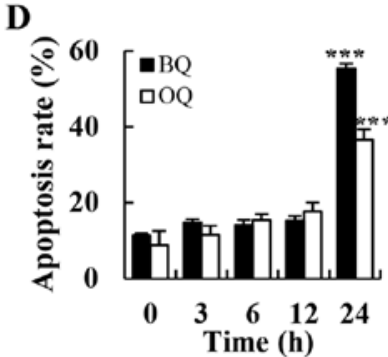
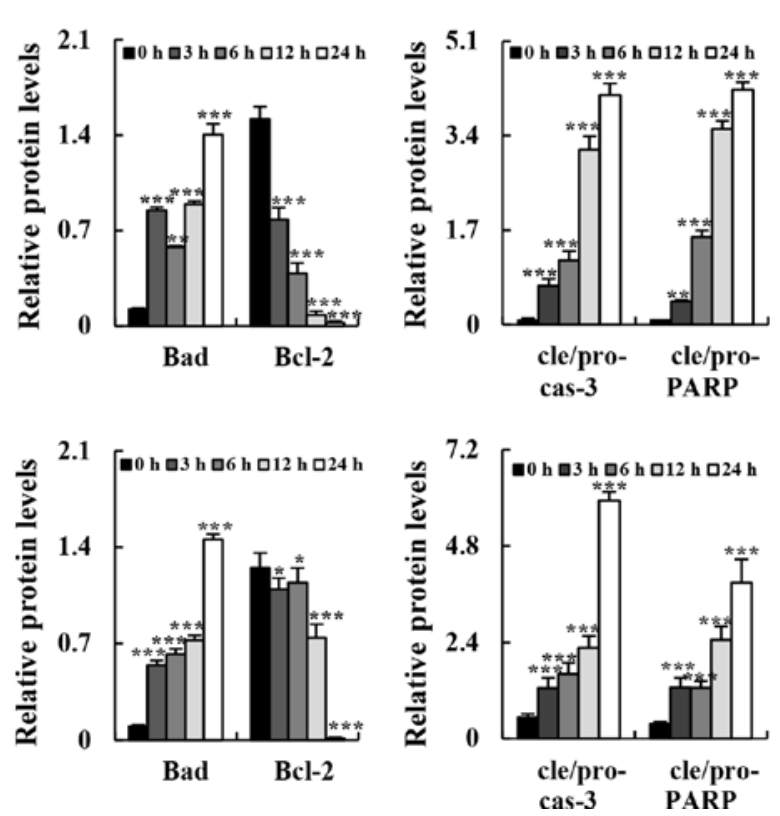

Figure 3. Apoptotic effects of BQ and OQ in AGS cells. (A) Cells were treated with 5-FU, BQ and OQ for different time points (3, 6, 12 and 24 h), and stained with Annexin V-FITC/PI. Data shown represent fluorescence microscopic images (original magnifications, x200). (B) Quantification of fluorescent intensity. (C) Cells were incubated with Annexin V-FITC/PI and analyzed by flow cytometry. (D) Quantification of the percentage of apoptotic cells. (E) Western blotting with antibodies against Bad, Bcl-2, cle-cas-3 and cle-PARP. ${ }^{*} \mathrm{P}<0.05,{ }^{* *} \mathrm{P}<0.01$ and ${ }^{* * *} \mathrm{P}<0.001 .5$-FU, 5-fluorouracil; BQ, 2-(butane-1-sulfinyl)-1,4-naphthoquinone; OQ, 2-(octane-1-sulfinyl)-1,4-naphthoquinone; cle, cleaved; pro, precursor; cas-3, caspase-3; PARP, Poly (ADP-ribose) polymerase.

effects were greater than those in the 5-FU and shikonin positive control groups (Fig. 2A). The viability of human normal cell lines (GES-1, L-02 and IMR-90) was minimally affected after exposure to high concentrations $(100 \mu \mathrm{M})$ of the two novel 1,4-naphthoquinone derivatives (BQ and $\mathrm{OQ}$ ) compared with the 5-FU and shikonin groups (Fig. 2B). 
A

0 3

6 12 24 (h)
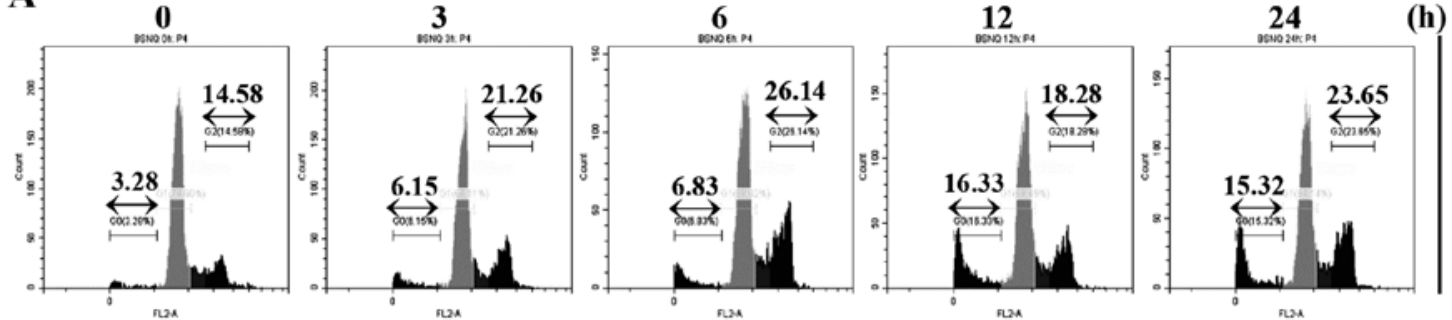

串
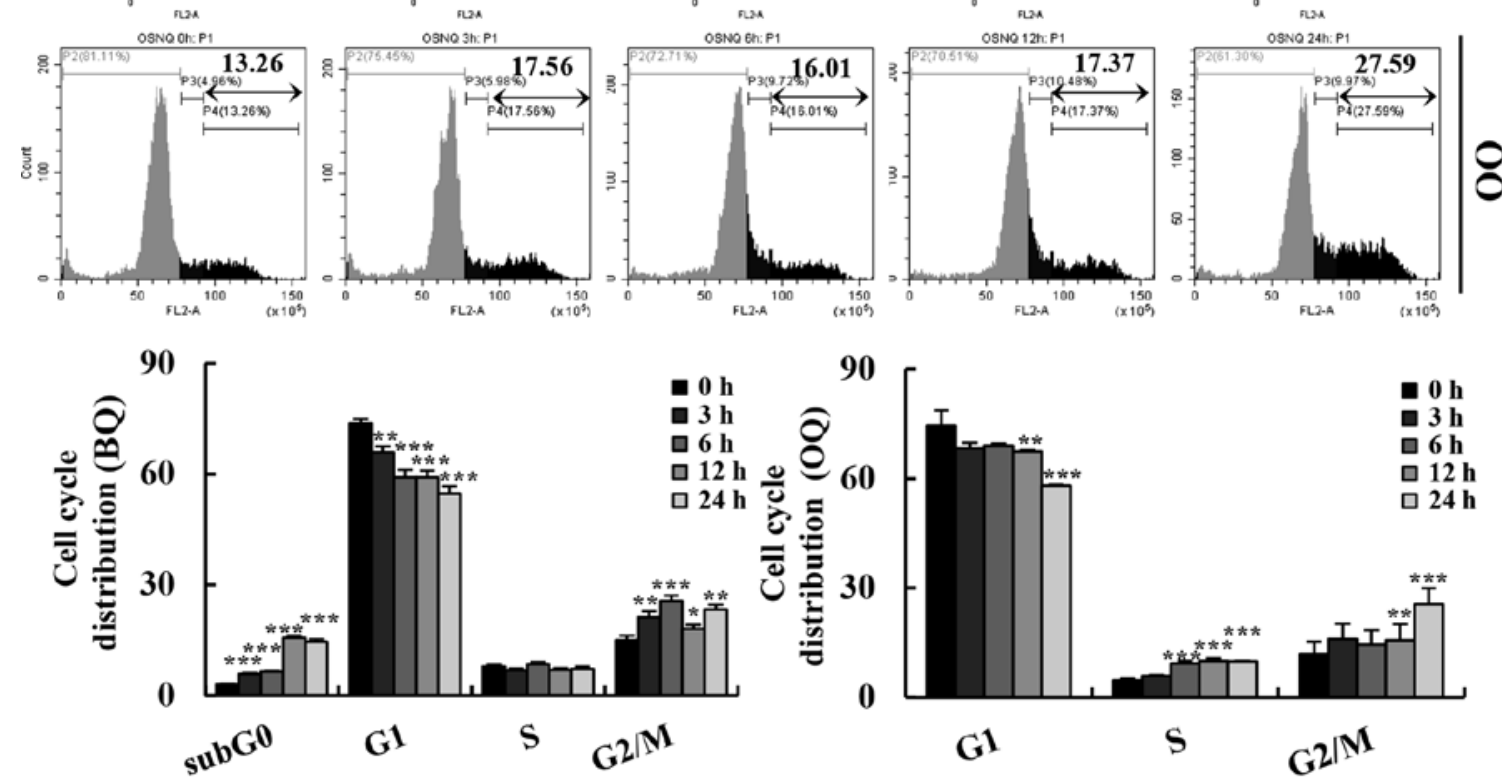

B
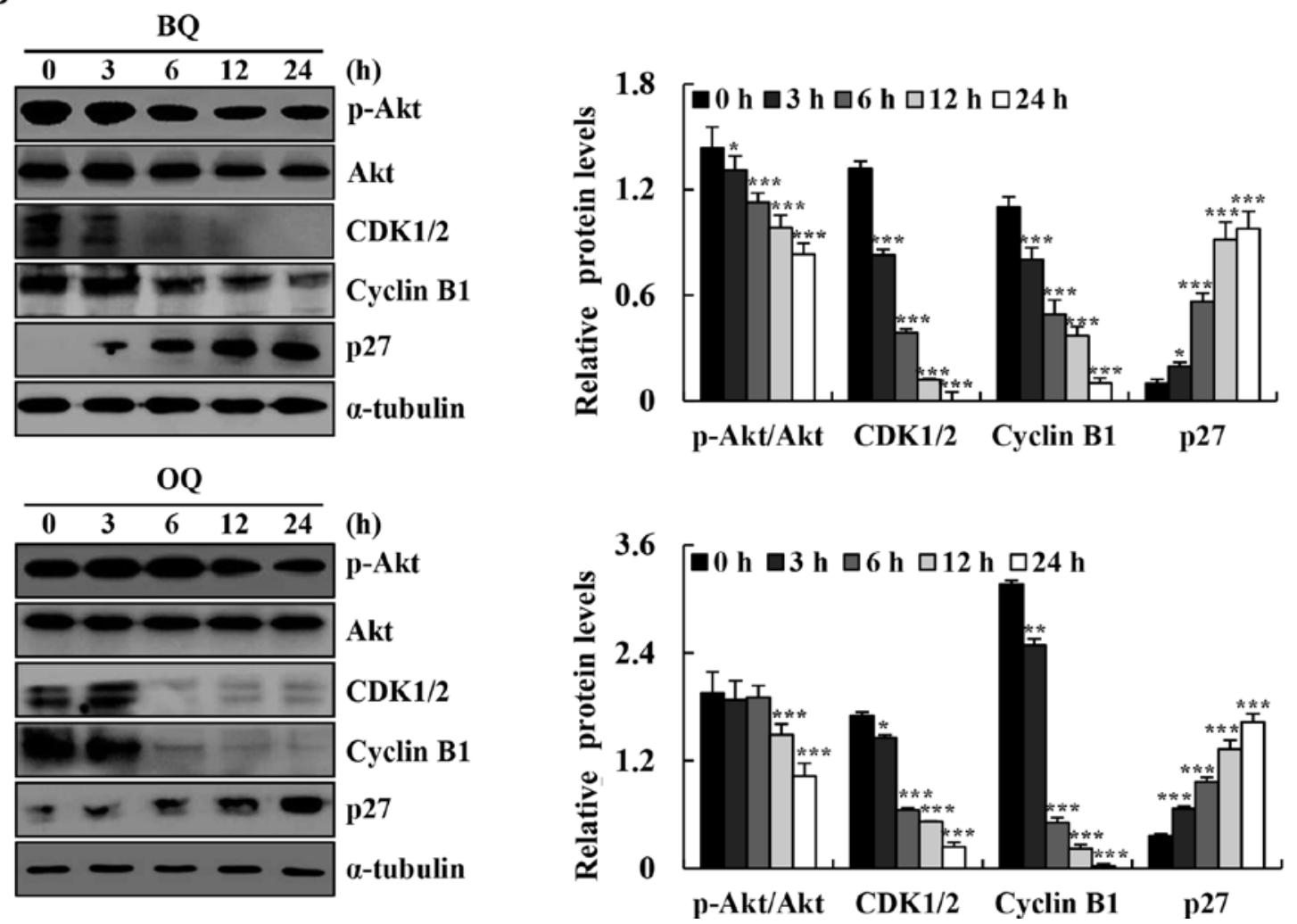

Figure 4. Effects of BQ and OQ on the cell cycle distribution and cell cycle checkpoint-related proteins in AGS cells. (A) Cells were stained with PI; DNA content was analyzed for cell cycle phase distribution by flow cytometry. (B) Western blotting with antibodies against cyclin B1, CDK1/2 and p27. "P<0.05, ${ }^{* *} \mathrm{P}<0.01$ and ${ }^{* * *} \mathrm{P}<0.001$. BQ, 2-(butane-1-sulfinyl)-1,4-naphthoquinone; OQ, 2-(octane-1-sulfinyl)-1,4-naphthoquinone.

Effects of $B Q$ and $O Q$ on the apoptosis of AGS cells. The results of flow cytometry and western blotting showed that BQ and OQ induced cell apoptosis in a time-dependent manner (Fig. 3A). The flow cytometry results showed that the population of apoptotic cells was significantly increased after treatment with $5 \mu \mathrm{M} \mathrm{BQ}$ (from approximately 10 to $54 \%$ ) 
A
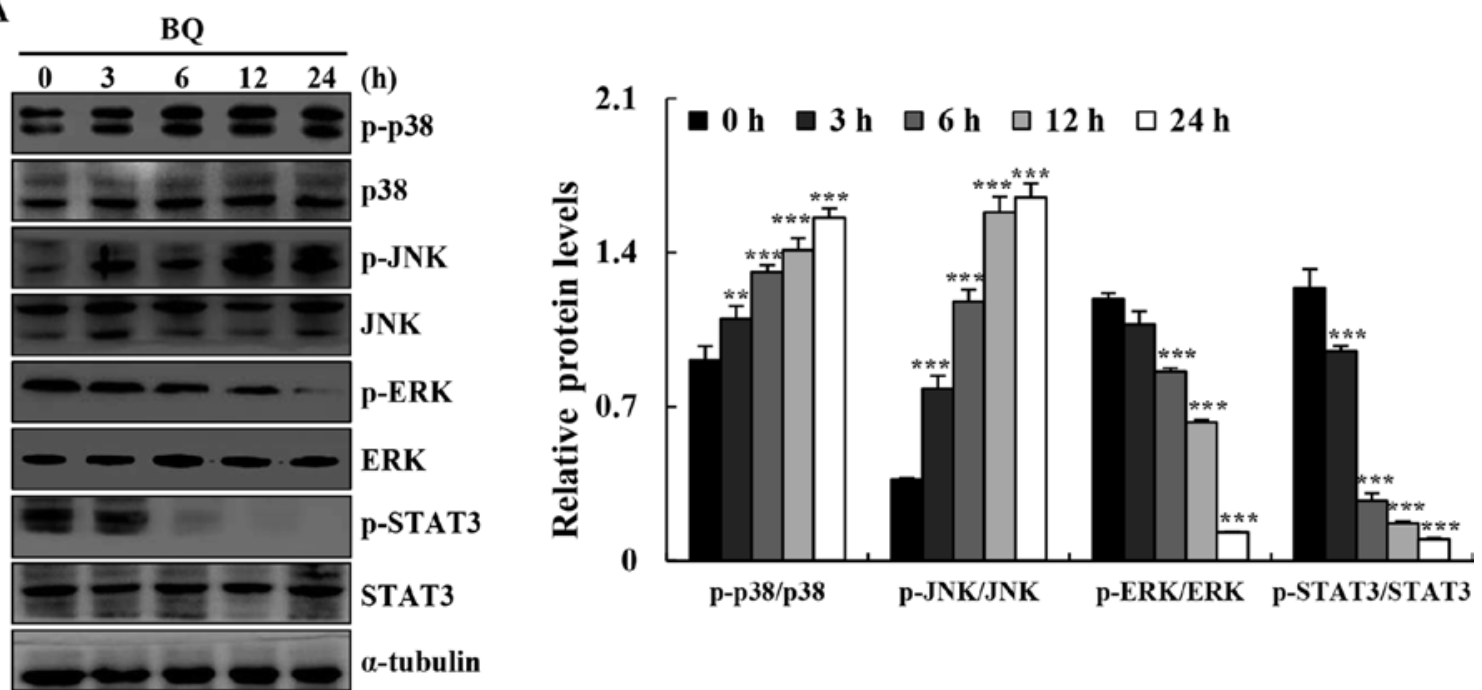

B
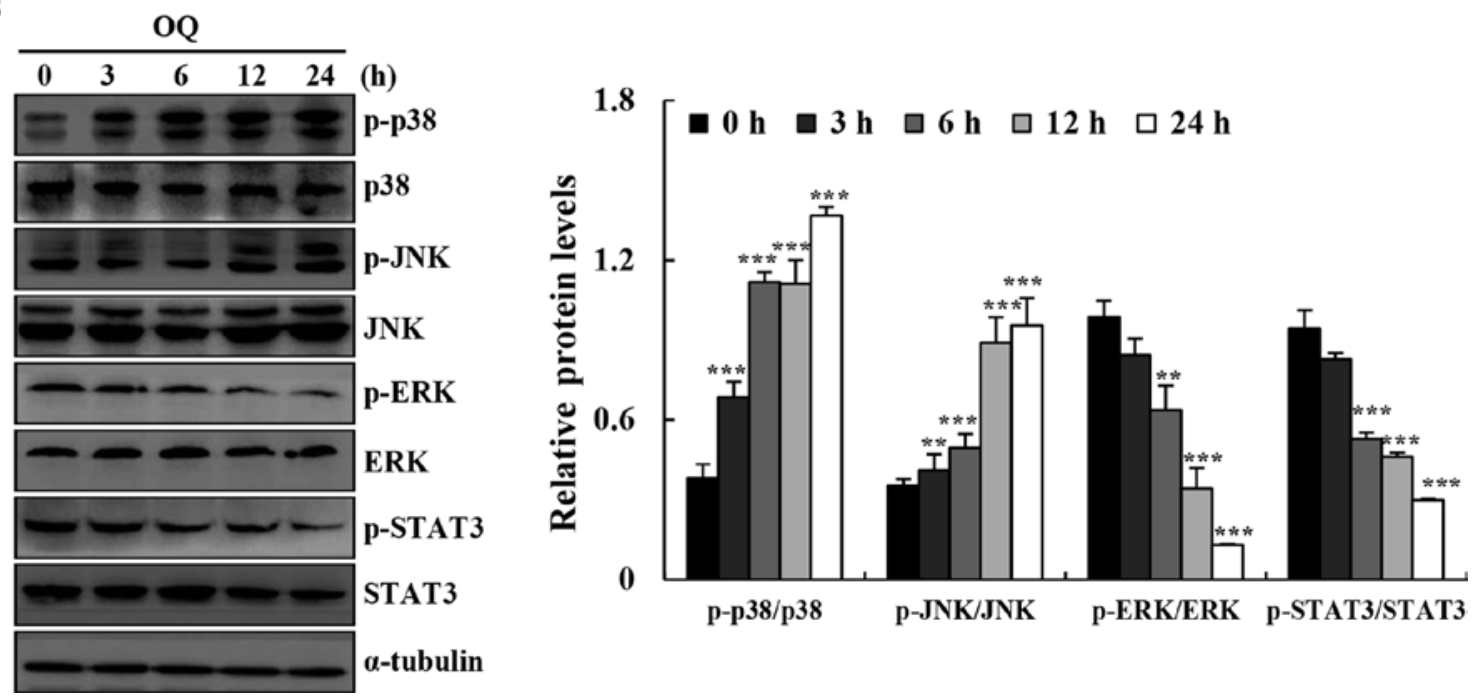

Figure 5. Effects of BQ and OQ on the MAPK, AKT and STAT3 signaling pathways in AGS cells. (A and B) Cells were treated with BQ and OQ for various time points $(3,6,12$ and $24 \mathrm{~h}$ ), and the expression levels of p-p38, p-JNK, p-ERK, p-AKT, and p-STAT3 were assessed by western blotting; $\alpha$-tubulin was used as an internal control. Data are expressed as the means \pm standard deviation of the results from three independent experiments. ${ }^{* *} \mathrm{P}<0.01$ and ${ }^{* * * *} \mathrm{P}<0.001$. $\mathrm{BQ}$, 2-(butane-1-sulfinyl)-1,4-naphthoquinone; OQ, 2-(octane-1-sulfinyl)-1,4-naphthoquinone; p-, phosphorylated.

and OQ (from approximately 10 to $37 \%$ ) in a time-dependent manner (Fig. 3C and D). In addition, BQ and OQ significantly increased the expression levels of pro-apoptotic protein Bad, cle-cas- 3 and cle-PARP and decreased the expression levels of the anti-apoptotic protein Bcl-2 in a time-dependent manner (Fig. 3E).

Effects of $B Q$ and $O Q$ on cell cycle arrest in AGS cells. The cell cycle distribution was assessed by flow cytometry and western blotting. BQ and $\mathrm{OQ}$ induced the accumulation of cells in the G2/M phase and decreased the cell population in the G1 phase (Fig. 4A). Meanwhile, BQ and OQ increased the expression levels of p27 and the expression levels of p-Akt, $\mathrm{CDK} 1 / 2$, and cyclin $\mathrm{B} 1$ were decreased in a time-dependent manner (Fig. 4B). These results indicated that BQ and OQ induced $\mathrm{G} 2 / \mathrm{M}$ phase cell cycle arrest and promoted apoptosis in gastric cancer cells through the Akt signaling pathway.

Effects of $B Q$ and $O Q$ on apoptosis through MAPK and STAT3 signaling pathways in AGS cells. We further determined the signaling pathways that mediated BQ- and OQ-induced AGS cell apoptosis. The expression levels of p38, JNK, ERK, and STAT3 signaling-related proteins were assessed in AGS cells after treatment with BQ and OQ by western blotting. BQ and OQ markedly upregulated the phosphorylation of p38 and JNK, and reduced the phosphorylation of ERK and STAT3 in AGS cells in a time-dependent manner (Fig. 5A and B).

Effects of $B Q$ and $O Q$ on ROS-mediated apoptosis in $A G S$ cells. To investigate the underlying relationship between the two compounds and ROS generation, we performed flow cytometry and western blotting. BQ and OQ significantly increased ROS generation in a time-dependent manner up to almost 1.8-fold compared to the untreated control (Fig. 6A), whereas pretreatment with NAC strongly inhibited BQ- and OQ-induced apoptosis (Fig. 6B). Furthermore, the levels of cle-cas-3 and cle-PARP and the phosphorylation levels of MAPK, Akt and STAT3 signaling pathway-related proteins were almost unchanged from the control condition following pre-treatment with NAC (Fig. 7A and B). These results suggest 
A

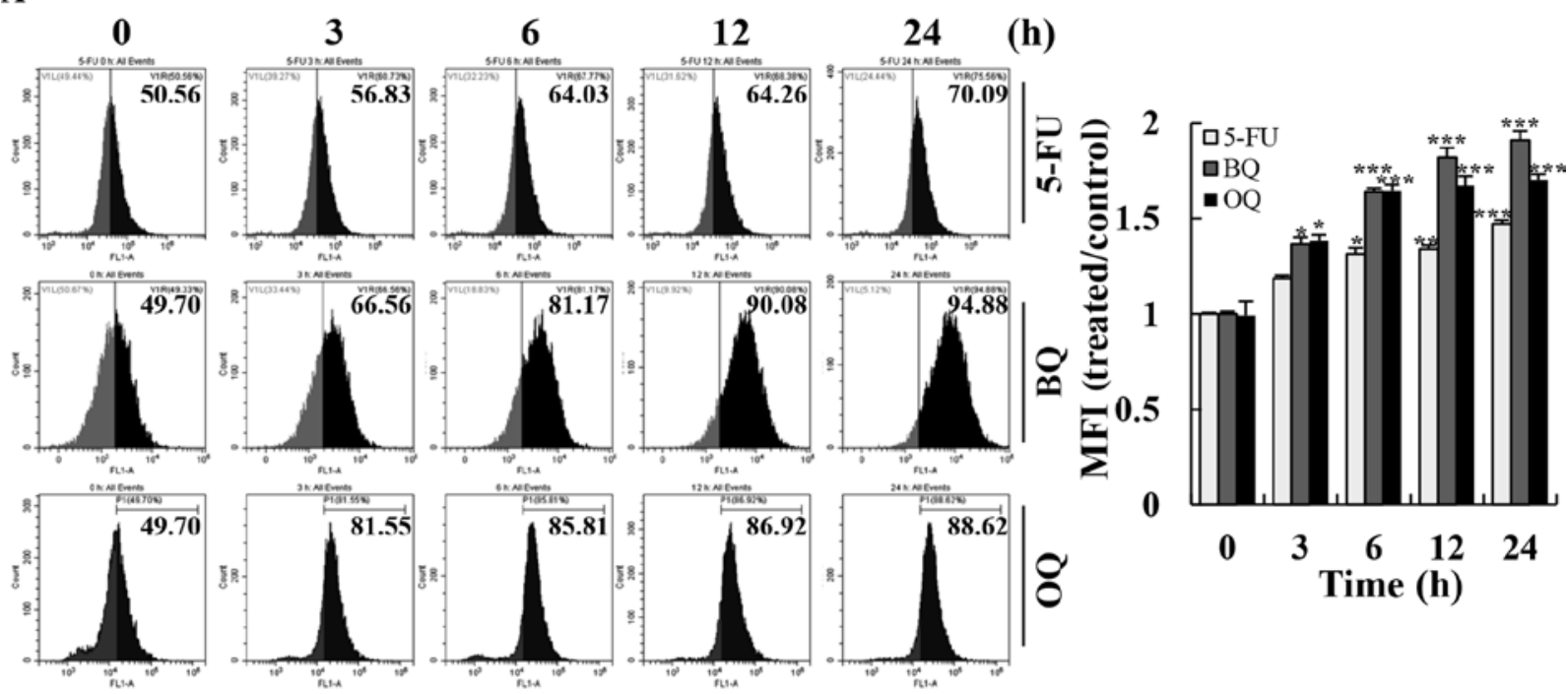

B
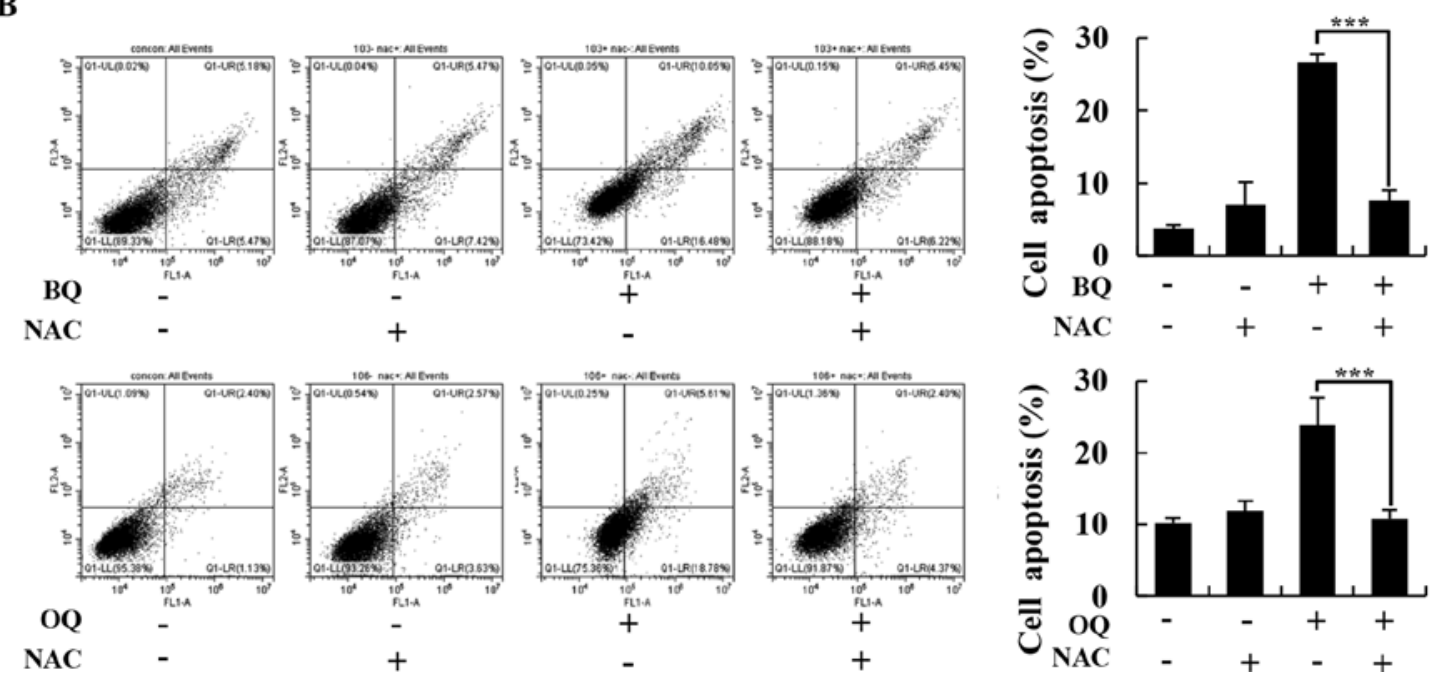

Figure 6. Effects of BQ and OQ on induced ROS-mediated apoptosis in AGS cells. (A) Cells were treated with 5-FU, BQ and OQ, and then the intracellular ROS levels were measured by flow cytometry (left panels) and mean fluorescence intensity (MFI) was quantitated (right panel). (B) Cells were treated with NAC for $30 \mathrm{~min}$ and then incubated with BQ and OQ for $24 \mathrm{~h}$. The intracellular apoptosis levels were measured by flow cytometry. Data are expressed as the means \pm standard deviation of the results from three independent experiments. ${ }^{*} \mathrm{P}<0.05,{ }^{* *} \mathrm{P}<0.01$ and ${ }^{* * *} \mathrm{P}<0.001 .5$-FU, 5-fluorouracil; $\mathrm{BQ}$, 2-(butane-1-sulfinyl)-1,4-naphthoquinone; OQ, 2-(octane-1-sulfinyl)-1,4-naphthoquinone; ROS, reactive oxygen species; NAC, N-acetyl-L-cysteine.

that ROS generation is required and plays an essential role in BQ- and OQ-triggered apoptosis in AGS cells.

\section{Discussion}

1,4-Naphthoquinones are active quinone derivatives that exhibit several different biological responses including anti-inflammatory, anticancer, apoptosis and radical scavenging activities (21); however, the severe side effects have limited their utility as clinical agents. To reduce their side effects and improve the effects of 1,4-naphthoquinone derivatives, BQ and OQ were synthesized and their potential mechanisms were explored in human gastric cancer cells. BQ and OQ significantly inhibited the viability of AGS and another seven human gastric cancer cell lines. Despite the fact that the two compounds share the same targets, the anticancer ability of BQ was more effective than that of OQ in AGS cells. It was speculated that this difference was caused by two reasons. First, the two compounds have low polarity and high lipid solubility, thus BQ with a lower molecular mass is more likely to cross the cell membrane and enter the cell to perform biological functions. Second, OQ with a longer carbon chain has good film-forming properties, thus its own effector group is not easily exposed for binding with the corresponding target molecule. To further illustrate the mechanism of cytotoxicity, apoptosis induction, cell cycle arrest, ROS generation and signaling-related protein expression were observed after BQ and OQ treatment in AGS cells.

As shown, compared with 5-FU, BQ and OQ had no significant cytotoxic effects on normal cells. The reason that BQ and OQ had low cytotoxicity in normal cells may be due to the fact that these cells have a strong antioxidant defense system and can resist oxidative stress damage. However, cancer cells have highly impaired antioxidant defense mechanisms, which may lead to ROS accumulation and oxidative stress (22). This is why BQ and OQ can inhibit the proliferation of cancer cells but demonstrate less inhibitory effects on normal cells. 
A

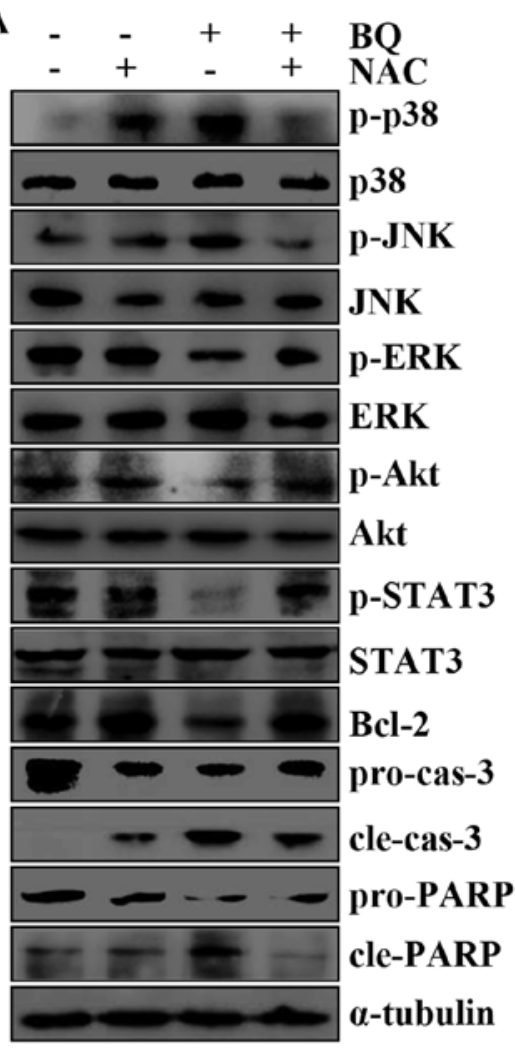

B

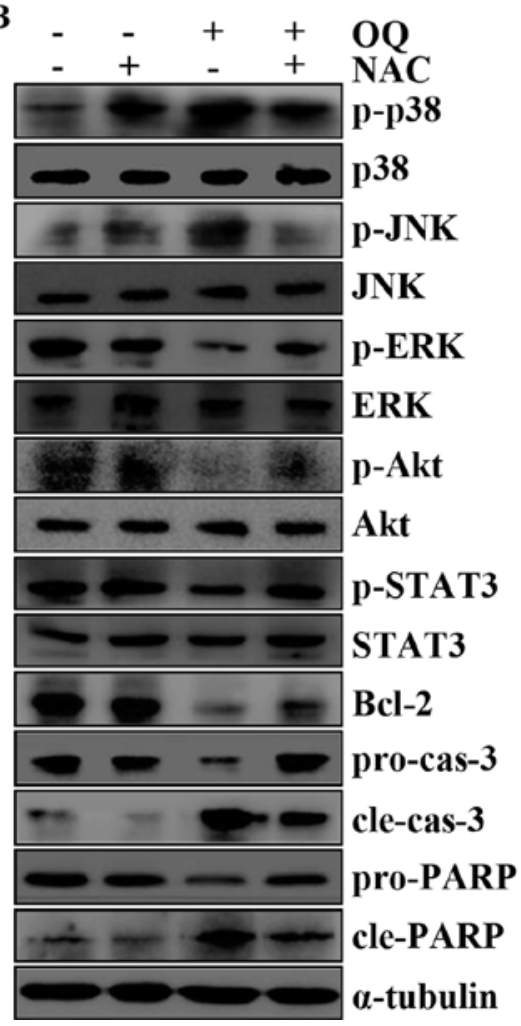

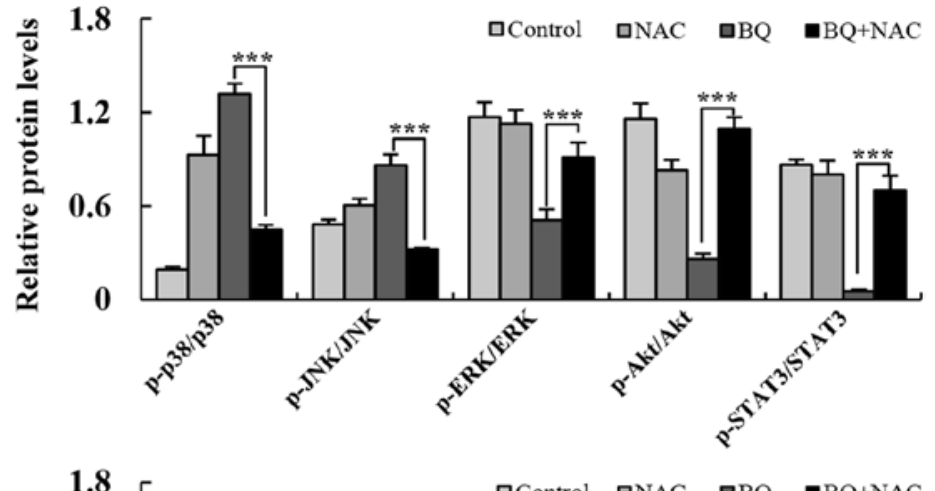
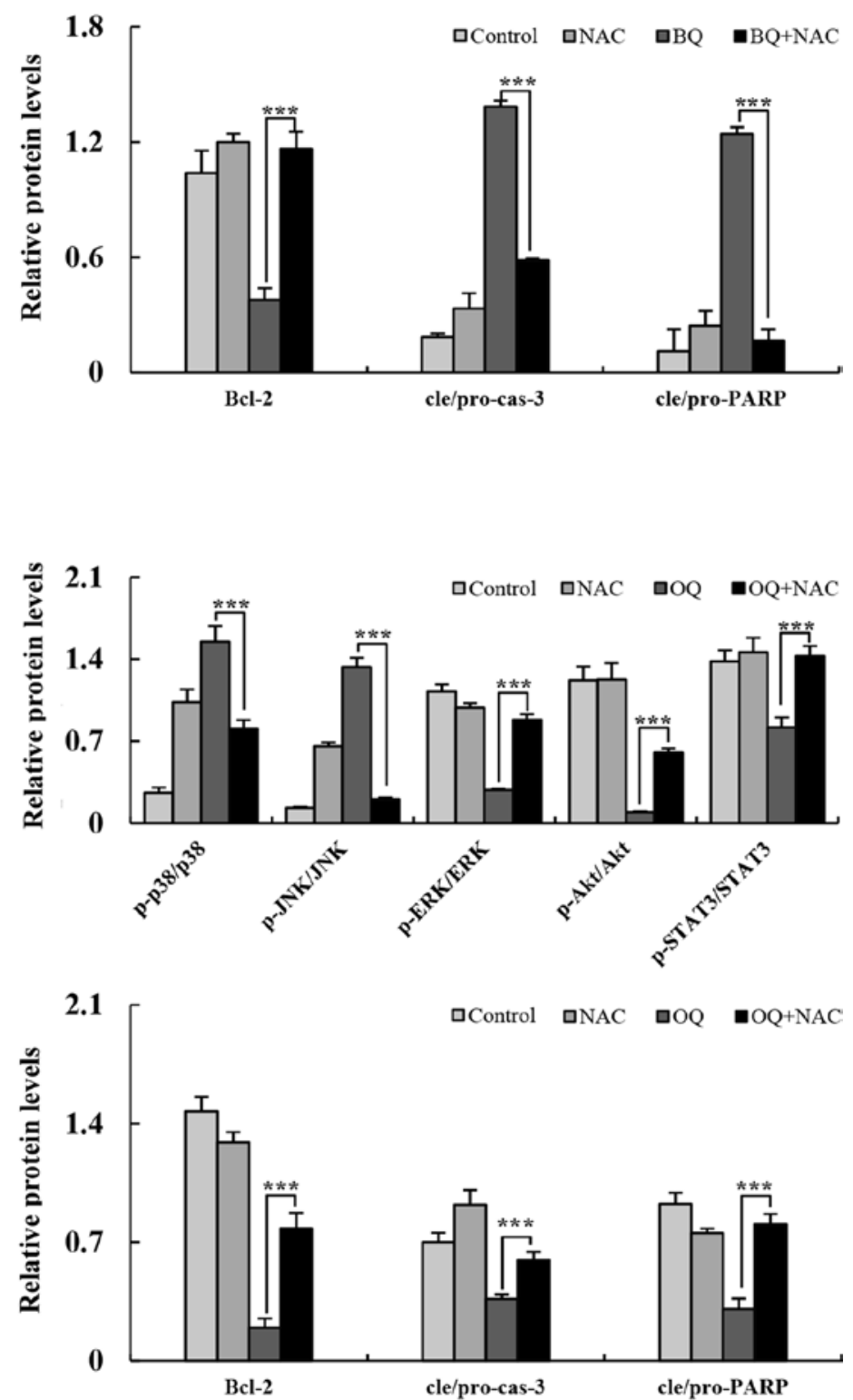

Figure 7. BQ and OQ induce ROS-mediated apoptosis via MAPK and STAT3 signaling pathways. (A and B) The expression levels of phosphorylated (p)-p38, p-JNK, p-ERK, p-AKT, p-STAT3, Bcl-2, cle-cas-3, pro-cas-3, pro-PARP and cle-PARP were detected by western blotting; $\alpha$-tubulin was used as an internal control. Data are expressed as the means \pm standard deviation of the results from three independent experiments. ${ }^{* * *} \mathrm{P}<0.001$. BQ, 2-(butane-1-sulfinyl)-1,4-naphthoquinone; OQ, 2-(octane-1-sulfinyl)-1,4-naphthoquinone; ROS, reactive oxygen species; NAC, N-acetyl-L-cysteine; p-, phosphorylated; cle, cleaved; pro, precursor; cas-3, caspase-3; PARP, Poly (ADP-ribose) polymerase.

The induction of apoptosis can effectively inhibit the growth of tumor cells, and is considered a novel target for cancer drug research and development (23). Some studies have reported that 1,4-naphthoquinone derivatives induce apoptosis in human cancer cells including breast, lung and colon cancer cells through the mitochondrial-dependent pathway (24-26). 


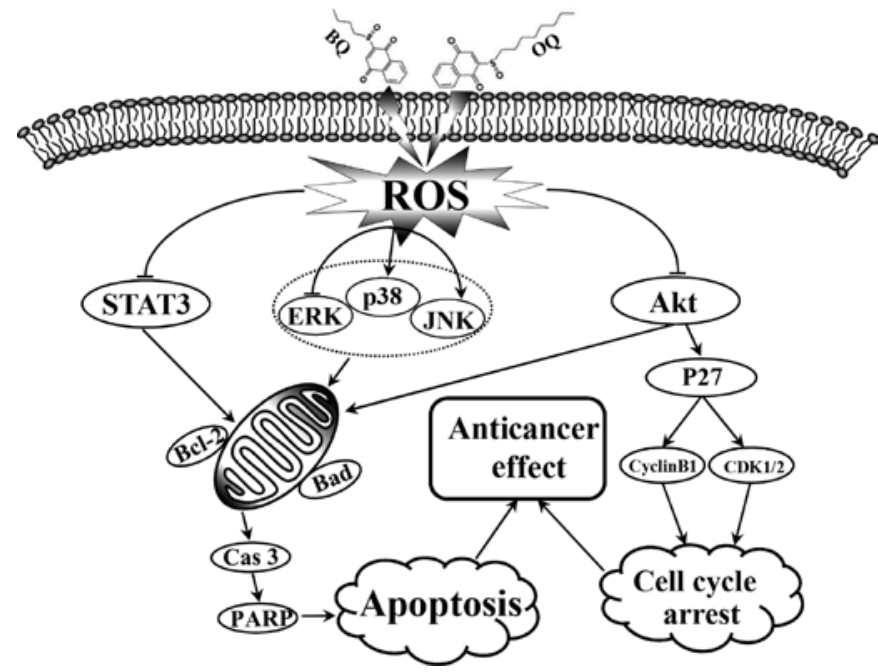

Figure 8. Schematic presentation of the signaling pathways in human gastric cancer cells affected by BQ and OQ. A proposed mechanism of BQ and OQ anticancer activity as related to the MAPK, AKT and STAT3 signaling pathways. BQ, 2-(butane-1-sulfinyl)-1,4-naphthoquinone; OQ, 2-(octane-1-sulfinyl)-1,4-naphthoquinone; Cas 3, caspase-3; ROS, reactive oxygen species.

The present results demonstrated that BQ and OQ activated Bcl-2, Bad, cle-caspase-3 and cle-PARP in gastric cancer cells. Mitochondrial apoptosis is partly dependent on the transition and release of Bcl-2 family proteins such as Bcl-2 and Bad (27). These results clearly suggest that $\mathrm{BQ}$ and $\mathrm{OQ}$ treatment leads to the induction of mitochondrial-dependent apoptosis in human gastric cancer AGS cells. Various naphthoquinone derivatives such as menadione and plumbagin can undergo oxidative stress-induced mitochondrial apoptosis by Fas-dependent pathways in cancer cells $(28,29)$. Therefore, it was speculated that the commonality of the compound structure between $\mathrm{BQ}$ and OQ can also induce mitochondrial-dependent apoptosis of cancer cells through the Fas ligand pathway, which will be verified in future studies.

Increasing research has focused on cell cycle regulation as a target for the development of anticancer drugs (30). This study showed that BQ and OQ treatment inhibited G2/M progression in AGS cancer cells, concomitant with the increased expression of $\mathrm{p} 27$ and the decreased expression of Akt, CDK1/2 and cyclin B1. However, the decrease in Akt was reversed by co-treatment with NAC, which is an ROS scavenger. These results suggest a strong link between cell cycle arrest and ROS generation. Research has demonstrated that ROS generation can inhibit the phosphorylation of Akt, thereby activating formation of the CDK1/cyclin B1 kinase complex (31). These results indicate that BQ- and OQ-induced cell cycle arrest is associated with ROS generation and p-Akt, CDK1/2, and cyclin B1 reduction.

MAPKs including p38, JNK and ERK play crucial roles in cell proliferation, survival and apoptosis. It has been reported that shikonin increases p-p38 levels but downregulates c-Myc to further inhibit DNA repair-induced apoptosis in NB4 cells (32). Decreased phosphorylation of ERK can affect the expression of multiple genes such as AQP5, Vav3 and PANS-4, which in turn induces the apoptosis of cancer cells (33-35). STAT3 belongs to the family of cytoplasmic latent transcription factors, which is associated with tumor progression and poor survival in gastric cancer. Plumbagin, a natural naphthoquinone, inhibits the growth of esophageal squamous cell carcinoma cells by downregulating the expression of STAT3 (36). To elucidate the exact mechanism involving BQ and OQ-induced apoptosis in human gastric cancer cells, the effects of two novel 1,4-naphthoquinone derivatives on activation of MAPKs and STAT3 were examined. The results showed that BQ and OQ markedly upregulated the phosphorylation of p38 and JNK, substantially reducing the phosphorylation of ERK and STAT3 in AGS cells in a time-dependent manner. Therefore, it appears that the MAPK and STAT3 signaling pathways play important roles in BQ and OQ-induced apoptosis.

ROS mediate intracellular signal cascades and excessive ROS production leads to cell apoptosis (37). It has been shown that half-redox potentials significantly influence ROS formation and possibly predict the cytotoxicity of quinone derivatives in cancer cells (38). The cytotoxicity of 1,4-naphthoquinones is related to their electron-accepting capability, which gives rise to ROS production leading to DNA damage and cancer cell apoptosis (39). Naphthoquinone derivatives also stimulate apoptosis via ROS-dependent mechanisms in various types of cancer cells (14). In the present study, it was illustrated that $\mathrm{BQ}$ and $\mathrm{OQ}$ could markedly induce the production of ROS. However, pretreatment with the ROS scavenger NAC prevented BQ- and OQ-induced apoptosis, showing that ROS play a significant role in BQ- and OQ-induced apoptosis in AGS cells (Fig. 6B). NAC significantly reversed the decrease in p-ERK and p-STAT3, and the increase in p-p38, p-JNK, cle-caspase- 3 and cle-PARP. BQ and OQ induced apoptosis involving the ROS-dependent MAPK and STAT3 pathways in AGS cells (Fig. 7A and B). These data suggest that the MAPK, STAT3 and AKT signaling pathways induced by the two novel 1,4-naphthoquinone derivatives were mediated by ROS.

In conclusion, the present study demonstrated that BQ and OQ induced G2/M phase cell cycle arrest and apoptosis in AGS cells via the ROS-mediated activation of MAPK, Akt and STAT3 signaling pathways (Fig. 8). From the different anticancer effects of the two compounds, substitution of these functional groups at the meta position appears to be an appropriate strategy for developing anticancer agents against AGS cells. This possibility will be investigated in vivo in further studies. In the present study, we examined the anticancer effects of the two derivatives and further determined the mechanism of apoptosis at the molecular level. In future research, the effects of the two derivatives should be evaluated in vivo.

\section{Acknowledgements}

Not applicable.

\section{Funding}

This study was funded by the Multigrain Production and Processing Characteristic Discipline Construction Project (grant no. 2042070010), and the Postdoctoral Scientific Research Foundation of Heilongjiang Province of China (grant no. LBH-Q13132). 


\section{Availability of data and materials}

The datasets used or analyzed during the present study are available from the corresponding author on reasonable request.

\section{Authors' contributions}

CHJ and CYW conceived and designed the study. HW, YHL, GNS, XJP, WTX, YZ, JRW and YCF performed the experiments. GNS, JQL, YZ, TZ, SNW, HX and HXW analyzed the data. HW and YHL wrote the manuscript. All authors read, edited and approved the final manuscript and agree to be accountable for all aspects of the research in ensuring that the accuracy or integrity of any part of the work are appropriately investigated and resolved.

\section{Ethics approval and consent to participate}

Not applicable.

\section{Patient consent for publication}

Not applicable.

\section{Competing interests}

The authors declare that they have no competing interests.

\section{References}

1. Jou E and Rajdev L: Current and emerging therapies in unresectable and recurrent gastric cancer. World J Gastroenterol 20: 4812-4823, 2016.

2. Lee SY and Oh SC: Changing strategies for target therapy in gastric cancer. World J Gastroenterol 3: 1179-1189, 2016.

3. HanG, Gong H, Wang Y,GuoS andLiu K:AMPK/mTOR-mediated inhibition of surviving partly contributes to metformin-induced apoptosis in human gastric cancer cell. Cancer Biol Ther 16 : 77-87, 2015.

4. Zhang C, Chen Z, Zhou X, Xu W, Wang G, Tang X, Luo L, Tu J, Zhu Y, Hu W, et al: Cantharidin induces $\mathrm{G}_{2} / \mathrm{M}$ phase arrest and apoptosis in human gastric cancer SGC-7901 and BGC-823 cells Oncol Lett 6: 2721-2726, 2014

5. Sinha K, Das J, Pal PB and Sil PC: Oxidative stress: The mitochondria-dependent and mitochondria-independent pathways of apoptosis. Arch Toxicol 87: 1157-1180, 2013.

6. Woo SM, Choi YK, Kim AJ, Cho SG and Ko SG: p53 causes butein-mediated apoptosis of chronic myeloid leukemia cells Mol Med Rep 13: 1091-1096, 2016.

7. Lan Q, Li S, Lai W, Xu H, Zhang Y, Zeng Y, Lan W and Chu Z: Methyl sartortuoate inhibits colon cancer cell growth by inducing apoptosis and G2/M-phase arrest. Int J Mol Sci 16: 19401-194118, 2015.

8. Lee H, Lee H, Chin H, Kim K and Lee D: ERBB3 knockdown induces cell cycle arrest and activation of Bak and Bax-dependent apoptosis in colon cancer cells. Oncotarget 5: 5138-5152, 2014.

9. Yang L, Zhou Y, Li Y, Zhou J, Wu Y, Cui Y, Yang G and Hong Y: Mutations of $\mathrm{p} 53$ and KRAS activate NF-kB to promote chemoresistance and tumorigenesis via dysregulation of cell cycle and suppression of apoptosis in lung cancer cells. Cancer Lett 357: 520-526, 2015

10. Kumar K, Sabarwal A and Singh RP: Mancozeb selectively induces mitochondrial-mediated apoptosis in human gastric carcinoma cells through ROS generation. Mitochondrion: Jun 11, 2018 (Epub ahead of print)

11. Duan F, Yu Y, Guan R, Xu Z, Liang H and Hong L: Vitamin K2 induces mitochondria-related apoptosis in human bladder cancer cells via ROS and JNK/p38 MAPK signal pathways. PLoS One 11: e0161886, 2016.
12. Cheng HB, Bo Y, Shen WX, Ren XG, Tan JN, Jia ZR and Xu CL: Longikaurin $\mathrm{E}$ induces apoptosis of pancreatic cancer cells via modulation of the p38 and PI3K/AKT pathways by ROS. Naunyn Schmiedebergs Arch Pharmacol 388: 623-634, 2015.

13. Rajamanickam V, Zhu H, Feng C, Chen X, Zheng H, Xu X, Zhang Q, Zou P, He G, Dai X, et al: Novel allylated monocarbonyl analogs of curcumin induce mitotic arrest and apoptosis by reactive oxygen species-mediated endoplasmic reticulum stress and inhibition of STAT3. Oncotarget 8: 101112-101129, 2017.

14. Zhang Q, Dong J, Cui J, Huang G, Meng Q and Li S: Cytotoxicity of Synthesized 1,4-Naphthoquinone Oxime derivatives on selected human cancer cell lines. Chem Pharm Bull (Tokyo) 66: 612-619, 2018.

15. Ghosh SK, Ganta A and Spanjaard RA: Discovery and cellular stress pathway analysis of 1,4-naphthoquinone derivatives with novel, highly potent broad-spectrum anticancer activity. J Biomed Sci 25: 12, 2018.

16. Farias MS, Pich CT, Kviecinski MR, Bucker NC, Felipe KB, Da Silva FO, Günther TM, Correia JF, Ríos D, Benites J, et al: Substituted 3-acyl-2-2-phenylamino-1,4-naphthoquinones intercalate into DNA and cause genotoxicity through the increased generation of reactive oxygen species culminating in cell death. Mol Med Rep 10: 405-410, 2014.

17. Ollinger $\mathrm{K}$ and Brunmark A: Effect of hydroxy substituentposition on 1,4-naphthoquinone toxicity to rat hepatocyt. J Biol Chem 266: 21496-22150, 1991.

18. Ball MD, Bartlett MS, Shaw M, Smith JW, Nasr M and Meshnick SR: Activities and conformational fitting of 1,4-Naphthoquinone Derivatives and other cyclic 1,4-Diones tested in vitro against Pneumocystis carinii. Antimicrob Agents Chemother 45: 1473-1479, 2001.

19. Suhara Y, Watanabe M, Motoyoshi S, Nakagawa K, Wada A, Takeda K, Takahashi K, Tokiwa H and Okano T: Synthesis of new vitamin $\mathrm{K}$ analogues as steroid and xenobiotic receptor (SXR) agonists: Insights into the biological role of the side chain part of vitamin K. J Med Chem 54: 4918-4922, 2011.

20. Abiko Y, Shinkai Y, Unoki T, Hirose R, Uehara T and Kumagai Y: Polysulfide $\mathrm{Na}_{2} \mathrm{~S}_{4}$ regulates the activation of PTEN/Akt/CREB signaling and cytotoxicity mediated by 1,4-naphthoquinone through formation of sulfur adducts. Sci Rep 7: 4814, 2017.

21. Bezkorovaynyj AO, Zyn AR, Harasym NM, Len JT, Figurka OM and Figurka DI: Loach embryos prooxidant-antioxidant status under the influence of amide derivatives of 1,4-naphthoquinone. Ukr Biochem J 88: 46-53, 2016.

22. Oh B, Figtree G, Costa D, Eade T, Hruby G, Lim S, Elfiky A, Martine N, Rosenthal D, Clarke S and Back M: Oxidative stress in prostate cancer patients: A systematic review of case control studies. Prostate Int 4: 71-87, 2016.

23. Zhang L, Zheng YX, Deng HZ, Liang L and Peng J: Aloperine induces $\mathrm{G} 2 / \mathrm{M}$ phase cell cycle arrest and apoptosis in HCT116 human colon cancer cells. Int J Mol Med 33: 1613-1620, 2014.

24. Ma WD, Zou YP, Wang P, Yao XH, Sun Y, Duan MH, Fu YJ and Yu B: Chimaphilin induces apoptosis in human breast cancer MCF-7 cells through a ROS-mediated mitochondrial pathway. Food Chem Toxicol 70: 1-8, 2014.

25. Ong JY, Yong PV, Lim YM and Ho AS: 2-Methoxy-1, 4-naphthoquinone (MNQ) induces apoptosis of A549 lung adenocarcinoma cells via oxidation-triggered JNK and p38 MAPK signaling pathways. Life Sci 135: 158-164, 2015.

26. Eldhose B, Gunawan M, Rahman M, Latha MS and Notario V: Plumbagin reduces human colon cancer cell survival by inducing cell cycle arrest and mitochondria-mediated apoptosis. Int $\mathbf{J}$ Oncol 45: 1913-1920, 2014

27. Zhang YL, Zhang R, Xu HL, Yu XF, Qu SC and Sui DY: 20(S)-protopanaxadiol triggers mitochondrial-mediated apoptosis in human lung adenocarcinoma A549 cells via inhibiting the PI3K/Akt signaling pathway. Am J Chin Med 41: 1137-1152, 2013.

28. Laux I and Nel A: Evidence that oxidative stress-induced apoptosis by menadione involves Fas-dependent and Fas-independent pathways. Clin Immunol 101: 335-344, 2001.

29. McKallip RJ, Lombard C, Sun J and Ramakrishnan R: Plumbagin-induced apoptosis in lymphocytes is mediated through increased reactive oxygen species production, upregulation of Fas, and activation of the caspase cascade. Toxicol Appl Pharmacol 247: 41-52, 2010.

30. Tian R, Li Y and Gao M: Shikonin causes cell-cycle arrest and induces apoptosis by regulating the EGFR-NF- $\kappa \mathrm{B}$ signalling pathway in human epidermoid carcinoma A431 cells. Biosci Rep 35: pii: e00189, 2015. 
31. Xu N, Lao Y, Zhang Y and Gillespie DA: Akt: A double-edged sword in cell proliferation and genome stability. J Oncol 2012: 951724, 2012.

32. Shan ZL, Zhong L, Xiao CL, Gan LG, Xu T, Song H, Yang R, Li L and Liu BZ: Shikonin suppresses proliferation and induces apoptosis in human leukemia NB4 cells through modulation of MAPKs and c-Myc. Mol Med Rep 16: 3055-3060, 2017.

33. Yang J, Zhang JN, Chen WL, Wang GS, Mao Q, Li SQ, Xiong WH, Lin YY, Ge JW, Li XX, et al: Effects of AQP5 gene silencing on proliferation, migration and apoptosis of human glioma cells through regulating EGFR/ERK/p38 MAPK signaling pathway. Oncotarget 8: 38444-38455, 2017.

34. Tan BB, Zhang MM, Li Y, Zhao Q, Fan LQ, Liu Y and Wang D: Inhibition of Vav3 gene can promote apoptosis of human gastric cancer cell line MGC803 by regulating ERK pathway. Tumour Biol 37: 7823-7833, 2016.

35. Yuan Z, Guo W, Yang J, Li L, Wang M, Lei Y, Wan Y, Zhao X, Luo N, Cheng P, et al: PNAS-4, an Early DNA damage response gene, induces $S$ phase arrest and apoptosis by activating checkpoint kinases in lung cancer cells. J Biol Chem 290: 14927-14944, 2015.

36. Cao Y, Yin X, Jia Y, Liu B, Wu S and Shang M: Plumbagin, a natural naphthoquinone, inhibits the growth of esophageal squamous cell carcinoma cells through inactivation of STAT3. Int J Mol Med 42: 1569-1576, 2018.
37. Zhong WF, Wang XH, Pan B, Li F, Kuang L and Su ZX: Eupatilin induces human renal cancer cell apoptosis via ROS-mediated MAPK and PI3K/AKT signaling pathways. Oncol Lett 12: 2894-2899, 2016.

38. Verrax J, Delvaux M, Beghein N, Taper H, Gallez B and Buc Calderon P: Enhancement of quinone redox cycling by ascorbate induces a caspase-3 independent cell death in human leukaemia cells. An in vitro comparative study. Free Radic Res 39: 649-657, 2005.

39. Prachayasittikul V, Pingaew R, Worachartcheewan A, Nantasenamat C, Prachayasittikul S, Ruchirawat S and Prachayasittikul V: Synthesis, anticancer activity and QSAR study of 1,4-naphthoquinone derivatives. Eur J Med Chem 84: 247-263, 2014.

(i) $\Theta$ This work is licensed under a Creative Common Attribution-NonCommercial-NoDerivatives 4.0 International (CC BY-NC-ND 4.0) License. 